Res Publica. Revista de Historia de las Ideas Políticas ISSN-e: 1989-6115

\title{
Hannah Arendt: lectura politológica del juicio del gusto de Kant
}

\author{
Sissi Cano Cabildo*
}

Recibido: 16 de septiembre de 2018 / Aceptado: 10de junio de 2019

Resumen. Arendt plantea la importancia de juzgar el mundo público como una condición necesaria para alcanzar el poder de la ciudadanía. Ahora bien, esta capacidad de juzgar no ha de ser resultado de la manipulación, ni de cualquier opinión improvisada; sino de la aplicabilidad del juicio del "gusto" de Kant al ámbito político. Arendt considera que las características del juicio del gusto de Kant deberían ser aplicables al ámbito político porque: amplía los márgenes de comprensión, se construye en el ámbito público, devela la comunicabilidad universal de los sentimientos, se construye a partir de la intersubjetividad y no de la "verdad", y deja ver que no todo es estratégico, que el goce desinteresado de la experiencia estética es humanamente posible no sólo respecto al arte, sino respecto a la humanidad y a la vida misma.

Palabras clave: juicio; gusto; política; comprensión.

\section{[en] Hannah Arendt: Politological Reading of Kant's Taste Judgment}

Abstract: Arendt assess the importance of judging the public world as a necessary condition to achieve the power of citizenship. Having said that, this ability to judge must not be the result of manipulation, nor of any impromptu opinion; but of the applicability of Kant's judgment of taste to the political sphere. Arendt considers that the characteristics of Kant's judgment of taste should be applicable to the political sphere because: it broadens the margins of comprehension, built in the public sphere, it reveals the universal communicability of feelings, it is builted from intersubjectivity and not from the "truth", and it show that not everything is strategic, that the disinterested enjoyment of the aesthetic experience is humanly possible not only with respect to art, but with respect to humanity and to life itself.

Keywords: Judgment; Taste; Politics; Comprehension.

Sumario. 1. Importancia política del Juicio. 2. El gusto como sentido de orientación política. 3. Elementos de aplicabilidad del juicio del gusto de Kant al ámbito político. 3.1. Los juicios del gusto amplían los márgenes de comprensión. 3.2. Los juicios del gusto se construyen en el ámbito público. 3.3. Los juicios del gusto no buscan la "verdad". 3.4. Comunicabilidad universal de los sentimientos en los juicios del gusto. 3.5. Goce desinteresado en los juicios del gusto. 4. Conclusión

Cómo citar: Cano Cabildo, S. (2019). Hannah Arendt: lectura politológica del juicio del gusto de Kant, en Res Publica 22.2, 445-460.

\footnotetext{
* Universidad Complutense de Madrid sicano@ucm.es
} 
El sentido del gusto es con el que amamos al mundo. Hannah Arendt

Cuando se habla de las cualidades humanas que entran en juego en la política se tiende a subrayar la importancia de la astucia, carisma, ser un buen orador, visión estratégica, etc., pero si habláramos de la importancia del sentido del "gusto" en la política, quizá parezca un poco raro. Esta es la lectura que ofrece Hannah Arendt y que me parece interesante rescatar, sobre todo porque recupera elementos como la sensibilidad y la imaginación para comprender mejor la realidad política.

Arendt encuentra en el juicio del gusto de Kant ciertos elementos que deberían recuperarse para juzgar el ámbito político y los argumentos al respecto son los que le darán sustento a este trabajo. En este sentido, el presente artículo aplicará una suerte de interaccionismo hermenéutico en cuanto que no versa sobre mi lectura del juicio del gusto de Kant sino acerca de la lectura que hace Arendt al respecto. Interpretación que ha sido polémica en muchos sentidos... sobretodo por que esta investigación no pudo terminarla por su fallecimiento en 1975; lo que tenemos al respecto son publicaciones póstumas de este tema en el apéndice de La vida del espíritu y la recopilación de sus trabajos publicados como Conferencias sobre Filosofía Política de Kant. También contamos con otros libros donde Arendt deja ver su interpretación de la estética kantiana pero de forma un tanto dispersa y circunstancial como el Diario filosófico, el artículo "Crisis de la cultura" y "Comprensión y Política" publicado en De la historia a la acción, la primera parte de ¿Qué es la política?, Hombres en tiempos de oscuridad, Entre el pasado y el futuro y Responsabilidad y Juicio.

Por otra parte, en este artículo me remitiré básicamente a la Crítica del Juicio porque es la obra que trabajó Arendt para plantear su lectura politológica del juicio del gusto, aunque también es verdad que en este tema Arendt a veces se remite a otras obras de Kant como la Antropología o Sobre la paz Perpetua, omitiendo otras tantas que hubieran sido muy esclarecedoras como la Crítica de la Razón Pura, donde Kant aborda el tema de la sensibilidad y de la imaginación, el ensayo "Teoría y práctica" o el tratado Sobre Pedagogía donde también analiza la facultad del juicio; pero no hay que olvidar que Arendt dejó inconclusa esta obra, con lo cual dejó abiertas preguntas, críticas y limitaciones inevitablemente.

Esta lectura politológica del sentido del gusto de Kant sintoniza con la opinión de Jaspers que "Kant fue, en efecto, un pensador político del más alto rango"" y esto se deja ver sobretodo en su aspiración a una sociedad de ciudadanos del mundo, en su reclamo de la dignidad y la libertad, conceptos que bien sabemos cambiaron el rumbo de la Filosofía política. Ahora bien, el enfoque arendtiano del juicio estético kantiano no presupone que el arte deba tener fines políticos o que el arte moralice a las personas, sólo rescata la actividad espiritual que hace posible el juicio del gusto para aplicarlo a la participación pública, como lo analizaremos en este artículo.

Arendt no apela a la razón práctica, ni al intelecto ${ }^{2}$ para actualizar al zoon politikon, sino al juicio estético porque sus condiciones de posibilidad son la libertad de

K. Jaspers, Los grandes filósofos. Los fundadores del filosofar: Platón, Agustín, Kant, trad. P. Simón, Madrid, Tecnos, 1995, p. 326.

2 Arendt traduce Verstand como intellect (intelecto) y no como understanding (entendimiento), modo habitual de verter el término. Aunque Mary McCarthy le decía que debería traducirse como entendimiento, Arendt nunca 
juzgar y la apertura a la otredad para participar en la creación de acuerdos intersubjetivos e imparciales; aspectos fundamentales para construir el horizonte político. Que la capacidad para juzgar sea política se deja ver sobre todo en la pluralidad que exige el hecho mismo de juzgar porque si el juzgar se diera en soledad no tendría sentido, sería sólo un monólogo o un ejercicio de autorreflexión. La diferencia y la pluralidad son inherentes al ámbito público, que es el lugar de lo político. El ejercicio del juicio implica la existencia de personas con puntos de mira diferentes dispuestas a dialogar, lo que exige ejercer la libertad, valor central para la política y asimismo, los fenómenos políticos se acercan a los estéticos porque ambos son la expresión de una capacidad específicamente humana: hacer algo nuevo, libre y que se puede compartir con los demás.

Los argumentos de este artículo los dividiré en tres partes: primero, explicaré la importancia política de juzgar, luego analizaré el "gusto" como sentido de orientación política y finalmente plantearé ciertas analogías ${ }^{3}$ entre el sentido arendtiano del juicio político y el enfoque kantiano del juicio del gusto. Voy a los argumentos.

\section{Importancia política del Juicio}

Para comprender la importancia política del juicio hay que puntualizar que el sentido arendtiano de la política se refiere a la libre organización y participación pública ${ }^{4}$; no a alguna forma de gobierno en particular, ni a alguna función burocrática, ni mucho menos a alguna organización maquiavélica. De manera que cuando Arendt habla de las cualidades humanas que entran en juego en la política, se está refiriendo a las actividades espirituales que cualquier ciudadano habría de ejercer en el ámbito público: pensamiento, juicio y voluntad 5 .

La importancia de ejercer el pensamiento en el ámbito ético-político radica principalmente en su función preventiva, en cuanto que la autorreflexión nos previene de la "banalidad del mal" y con esto, de la ambigüedad del concepto de maldad por el que algunas personas están más prestas a la manipulación y a la irresponsabilidad burocrática; banalidad que no minimiza la crueldad de sus efectos en lo privado y en lo público. Ahora bien, el pensamiento por sí sólo no garantiza la participación pública, faltaría ampliar los márgenes de sensibilidad y de imaginación por la otredad, tener la disposición desinteresada y abierta para participar en la deliberación y en la creación de acuerdos imparciales, lo que correspondería a aplicar el juicio del gusto de Kant al ámbito público.

El juicio es una de las condiciones de posibilidad para la participación política porque justamente al juzgar, los ciudadanos construyen el mundo de la intersubjetividad y de las decisiones públicas; de lo contrario, todo quedaría en ideales, pensa-

aceptó porque consideraba que si bien Verstand es el sustantivo de verstehen (entendimiento), en las traducciones habituales carece de connotaciones propias del das Verstehen alemán. Cf. H. Arendt, La vida del espíritu, trad. C. Corral y F. Birulés, Barcelona, Paidós, 2002, pp. 16 y 40.

3 Me refiero a analogías en el sentido de semejanzas, sin apuntar al sentido riguroso que tienen las analogías en la Crítica de la Razón Pura.

4 Cf. H. Arendt, ¿Qué es la politica?, trad. R. Sala Carbó, Barcelona, Paidós, I.C.E./U.A.B., 1997, pp. 45-46. Aunque realmente esta idea está presente en casi todas las obras de Arendt.

5 Temas que Arendt aborda en muchas de sus obras pero fundamentalmente en La vida del espíritu como ejes temáticos. 
mientos y "buenas intenciones", dando margen a que otros decidan, a riesgo de lo que sea...

Arendt consideraba que uno de los peligros de las sociedades contemporáneas es que las estructuras burocráticas, tecnocráticas y despolitizadas de la vida moderna fomentan la indiferencia y hacen que los hombres sean menos críticos y menos inclinados a asumir responsabilidades. Y ésto es lo que justamente le conviene a las élites porque es mucho más fácil dominar y explotar a ciudadanos pasivos y obedientes, ¿a qué ha llevado la resignación de los hombres que creyeron que los problemas del mundo ocurrían por alguna voluntad exógena e inapelable (Dioses, Destino, Fortuna, etc.)? Por esto y más, a lo que quiero llegar es a sugerir que para alcanzar formas de gobierno más justas, es fundamental ejercer el derecho de juzgar y denunciar lo que pasa en el ámbito público. Hay situaciones-límite que el ser humano debería evitar y denunciar: la guerra, la violación, la corrupción, el terrorismo, etc.; son problemas públicos que no deben ser aceptados con resignación.

Arendt confiaba en la importancia de la participación pública y en la responsabilidad que tenemos todos los seres humanos de crear un mundo mejor, que por supuesto implica atreverse a pensar por uno mismo y ejercer el derecho la crítica. Al juzgar actuamos como ciudadanos, nos reconocemos como iguales y a su vez, esos iguales nuestros también juzgan nuestras acciones. Juzgar sería de esta manera una de las capacidades fundamentales de toda ciudadanía que podría protegernos de cualquier suerte de manipulación pero al respecto también hay que aclarar que la responsabilidad de velar por el espacio público no ha de confundirse con la intromisión a la privacidad, ámbito que paradójicamente se "vende" y promueve en nuestra sociedad del espectáculo. Muy por el contrario, Arendt recupera de la polis la siguiente idea: "Lo privado era semejante al aspecto oscuro y oculto de la esfera pública, y si ser político significaba alcanzar la más elevada posibilidad de la existencia humana, carecer de un lugar privado propio (como era el caso del esclavo) significaba dejar de ser humano". Con esto quise decir que Arendt recupera de los griegos (entre otras cosas) la isegoría y con ello, la libertad de expresión y la importancia de juzgar el ámbito público, pero asimismo la importancia de respetar el ámbito privado como una de las grandes conquistas de nuestros derechos individuales compatibles con la responsabilidad ciudadana.

Ahora bien, Arendt recupera la dimensión pública del juicio del gusto de Kant para efectos ético-políticos. No hay que olvidar que Kant había anunciado bajo el título de "Crítica del gusto moral" a su obra La metafísica de las costumbres, 30 años antes de que la terminara y publicara, de donde se entiende que en la Crítica del Juicio mencione que: "el gusto, en el fondo, es una facultad de juzgar la sensibilización de ideas morales" ". Sin embargo, es bien sabido que Kant terminará fundamentando su ética en la razón con los imperativos morales y a la ciencia con los juicios sintéticos a priori; mientras que Arendt no partirá de la razón sino que apelará al juicio del gusto para fundamentar la deliberación ético-política. Me explico. Empezaré citando de la Crítica del juicio de Kant:

El Juicio, en general, es la facultad de pensar lo particular como contenido en lo universal. Si lo universal (la regla, el principio, la ley) es dado, el Juicio, que sub-

H. Arendt, La condición humana, trad. R. Gil Novales, Barcelona, Paidós, 1993, p. 71.

I. Kant, Crítica del Juicio, trad. Manuel García Morente, Madrid, Colección Austral, 9a edic., 2001, p. 323. 
sume en él lo particular (incluso cuando como Juicio trascendental pone a priori las condiciones dentro de las cuales solamente puede subsumirse en lo general) es determinante. Pero si sólo lo particular es dado sobre el cual él debe encontrar lo universal entonces el juicio es solamente reflexionante ${ }^{8}$.

Al respecto, Ricoeur considera que la lectura kantiana del juicio revoluciona toda la tradición filosófica pues antes de Kant reposaba sobre la definición lógica del juicio como acto predicativo (referir un predicado a un sujeto). La inversión fundamental operada por Kant fue sustituir la idea de atribución por la de subsunción pero además de esto, ya en la Crítica del Juicio adopta la hipótesis de un funcionamiento inverso al de la subsunción, donde habla más bien de juicio reflexivo9

Arendt considera que es relativamente fácil explicar el proceso de subsunción del juicio determinante pero la dificultad aumenta para explicar lo general en el juicio reflexivo pues la pauta no se puede tomar de la experiencia y no puede tener su origen en el exterior. De ahí que para Kant, el juicio reflexivo necesite de un principio trascendental para fundar la unidad de todos los principios empíricos.

Por otra parte, Arendt considera que el juicio reflexivo tiene mucho más que ver con la capacidad de diferenciar que con la capacidad para subsumir y ordenar y no atribuye a la estupidez el desinterés por juzgar. La capacidad de discernir, de ejercer la moralidad del pensamiento que consiste en la distinción entre el bien y el mal, es independiente de la instrucción, la clase social y la inteligencia; Arendt considera que la línea que separa a los que juzgan de los que no lo hacen cruzan todas las diferencias sociales, culturales o educativas. "Ausencia de pensamiento no quiere decir estupidez; puede encontrarse en personas muy inteligentes, y no proviene de un mal corazón; probablemente sea a la inversa, que la maldad puede ser causada por la ausencia de pensamiento" 10 . Ahora que, ésto no ha de llevarnos a confundir el juicio reflexionante con el pensamiento, para nuestra filósofa de Königsberg el pensamiento opera con lo invisible, con representaciones de cosas que están ausentes y tiende a generalizar, mientras que el juicio siempre se ocupa de particulares y contingentes; pero ambas están interconectadas ${ }^{11}$. El juicio reflexivo no es resultado de la inferencia lógica del pensamiento, sólo quiere decir que el juicio reflexivo y el pensamiento están relacionados de forma semejante a como se interconectan la conciencia moral y la conciencia del mundo; por ejemplo, el hecho de juzgar que la rosa sea bella: no se juzga como tal porque se disponga de una regla universal de belleza, más bien ocurre que la rosa en particular genera en el sujeto el predicado de belleza. Así, la materia del juicio estético es juzgar esta rosa y sólo por extensión podemos ampliarlo a un juicio sobre todas las rosas ${ }^{12}$.

Ahora bien, la capacidad de sentir placer nacido de la reflexión sobre la forma de las cosas (de la naturaleza tanto como del arte) expresa también una finalidad del sujeto con relación a los objetos y así se deja ver que la "finalidad" regula los juicios reflexionantes pero dicha finalidad se enfrenta a una disyuntiva: el juicio reflexivo puede ser teleológico o estético; comprendiendo en el primero la facultad de juzgar

\footnotetext{
Ibidem, p.105.

9 Cf. P. Ricoeur, "Juicio estético y juicio político según Hannah Arendt” en Lo justo, trad. A. Domingo Moratalla, Madrid, Caparrós editores, 1995, p. 140.

10 H. Arendt, La vida del espiritu, op. cit., p. 24.

11 Ibidem, p. 215.

12 Cf. H. Arendt, Conferencias sobre la filosofía politica de Kant, trad. C. Corral, Barcelona, Paidós, 2003 , p. 207.
} 
la finalidad de la naturaleza mediante el entendimiento y la razón, y en el segundo la facultad de juzgar la finalidad formal (también llamada subjetiva) mediante el sentimiento de placer o dolor. Y es en el juicio estético donde Arendt encuentra elementos análogos al juicio político, primero por su enfoque humanista del sentido del gusto y luego por las condiciones de posibilidad que entran en juego al juzgar. Temas que analizaré en los siguientes apartados.

\section{El gusto como sentido de orientación política}

Para comprender mejor la viabilidad politológica del juicio hay que detenernos un poco en el sentido del gusto del Sujeto que juzga porque de ahí dependerá la orientación política y no propiamente de su nivel de información o de inteligencia. Sospecho que después de la militancia de Heidegger en el nazismo, Arendt reparó hasta qué punto el desarrollo intelectual conlleva a la solidaridad... Heidegger, una personalidad filosófica angular, a quien Arendt le dedicara en Las sombras su "indeclinable devoción a un solo ser", aunque más tarde se distanciaran por veinte años. En ese largo período Heidegger se adhiere al nazismo y Arendt emigra a Estados Unidos. De esta amistad, se podrá comprender mejor por qué algunos datos biográficos de Heidegger repercutieron tanto en Arendt, por ejemplo, el racismo de Heidegger -según Elisabeth Young-Bruehl- que se dejaba ver en su comportamiento frecuentemente ofensivo a la esposa judía de Jaspers. Heidegger nunca mostró alguna inconformidad de que su amigo Jaspers fuera excluido en 1933 de toda participación en la gestión académica por el hecho de estar casado con una judía, de que en 1937 perdiera la cátedra y de que incluso, dejaran de publicarse sus obras en Alemania ${ }^{13}$. En alguna ocasión, Jaspers diría de la filosofía heideggeriana que era un discurso altamente intelectual y abstracto pero "sin amor y, en consecuencia, carente de un estilo amable"14. En 1933 el rector de la Universidad de Friburgo se negó a dar curso a la notificación que prohibía dar clases a los judíos, notificación que Heidegger sí se atrevió a llevar a cabo sin algún reparo, incluso lo hizo con un desairado "nacionalismo", a partir de lo cual asumió el puesto de rector ${ }^{15}$. Posteriormente a Arendt le llegaron noticias de que Heidegger había expulsado a Husserl de la Universidad de Friburgo y que discriminaba a sus alumnos judíos. No obstante, pese a sus diferencias políticas, Hannah y Heidegger reanudan su relación en 1950 y continúan siendo amigos hasta la muerte de Hannah en 1975, a la que siguió unos meses después la de Heidegger.

A partir de ello no resulta extraño que Arendt considere que el pensamiento y la razón no garantizan ser más comprensivos, más bien hay que disponerse a dejarse afectar por la felicidad o por la desgracia de los demás. Un ánima abierta a los demás, de una u otra forma proyecta una calidad moral superior a los intereses egoístas del idion. En cierto sentido, el tipo de ánimo es un efecto de la fuerza moral.

La ausencia de emociones ni causa ni promueve la racionalidad. La "objetividad y ecuanimidad" ante la tragedia inaguantable pueden ser aterradoras (...) lo con-

Cf. E. Ettinger, Hannah Arendt y Martín Heidegger, trad. Daniel Najmías, Barcelona, Tusquets, 1996, p.75.

14 Cf. E. Young-Bruhel, Hannah Arendt, trad. M. Lloris Valdés, Valencia, edicions Alfons el Magnánim, 1993, p. 114.

15 Cf. Ibidem, p. 153. 
trario de lo emocional no es lo "racional", signifique lo que signifique, sino la incapacidad de dejarse conmover, que suele ser un fenómeno patológico, o bien el sentimentalismo, que es una perversión del sentimiento ${ }^{16}$.

La disposición estética (gr. aisthesis: sensibilidad) deja ver a qué cosas eres sensible. Arendt refiere como: "todos sabemos bien que las personas se reconocen con gran rapidez y de manera inequívoca pueden sentir que están hechas la una para la otra, cuando descubren una concordancia en lo que les agrada y desagrada"17. E1 gusto deja ver lo sensible que eres a determinado tipo de cosas, ideas o situaciones y así mismo, es una proyección del tipo de personalidad que tenemos.

Recordemos que en los inicios de la Filosofía el sentido del gusto tuvo un origen moral más que estético. La ética griega -la ética de la medida de los pitagóricos y de Platón, la ética de la mesotés creada por Aristóteles- es en su sentido más amplio una ética del buen gusto. Y este enfoque del gusto persistió hasta el s. XVIII como lo deja ver Gadamer en Verdad y método cuando refiere a Baltasar Gracián, para quien el gusto era la primera "espiritualización de la animalidad" porque consideraba que el discernimiento sensible del gusto no es en realidad mero instinto, el gusto sensorial contiene ya el germen de la distinción que se realiza en el enjuiciamiento espiritual de las cosas; y en este sentido, consideraba que la cultura (Bildung) no sólo se debe al ingenio (Geist) sino también al gusto $(\text { Geschmack })^{18}$. En sintonía, Schiller decía que: "educar la facultad sensible es la más urgente necesidad de nuestro tiempo, no sólo porque es un medio de hacer eficaces en la vida los progresos del saber, sino porque contribuye a la mejora del conocimiento mismo"19. Ya será Kant quien limpie a la ética de todos sus momentos estéticos y en este aspecto, el filósofo de Königsberg representa la ruptura con la tradición, restringiendo el concepto del gusto al ámbito de validez autónoma e independiente del juicio y evocando a la razón para el cumplimiento del deber-ser, al margen de cualquier inclinación estética.

Posteriormente, la pluralidad de enfoques humanísticos parecieran volver a vincular al gusto con otro tipo de motivos conscientes, preconscientes e inconscientes; sobre todo el psicoanálisis que dio constancia de cómo los gustos pueden proyectar datos de la personalidad de uno mismo, revelando inclinaciones y prejuicios que quizá conscientemente no podamos reconocer. Desde este enfoque, la razón y las ideas conscientes pueden engañar y ésto se puede comprobar mediante el mecanismo psicológico del autoengaño, llámese racionalización, deshonestidad, hipocresía o como sea. Los discursos conscientes sobre la vida pueden ser mentira mientras que los gustos siempre revelan la auténtica personalidad de uno mismo y de los demás, nos guste o no lo que nos gusta; el sentimiento es infalible, por lo que el sentido del gusto resulta tan revelador.

El "gusto" al escoger es discriminante, dice si algo agrada o desagrada. En materia de gustos más que en cualquier otra materia, toda determinación es negación; al preferir algo, de una u otra forma negamos todo lo demás. En este sentido, toda

16 H. Arendt, Sobre la violencia, trad. G. Solana, Madrid, Alianza editorial, 2005, pp. 86-87.

17 H. Arendt, "La crisis en la cultura: su significado político y social" en Entre el pasado y el futuro, trad. A. Poljak, Barcelona, Península, 1996, p. 235.

18 Cf. H.-G. Gadamer, Verdad y método, trad. A. Agud Aparicio y R. de Agapito, Salamanca, Sígueme, 1977, pp. 66-67.

19 J. Ch. F. Schiller, Escritos sobre estética, trad. M. García Morente, M. J. Callejo Hernanz y J. González Fisac, Madrid, Tecnos, 1990. p. 124. 
especie de gusto une y separa, ya que el gusto es el criterio de lo que se es para los otros, de aquello por lo que uno se clasifica y por lo que le clasifican. Y al comunicar los sentimientos, los placeres y goces desinteresados se expresan las preferencias y se eligen las compañías, así funciona "el gusto como principio de organización"20. E1 gusto funciona como una especie de sentido de la orientación social.

Pero también es verdad que el mejor de los gustos puede coincidir con los demás y es cuando hablamos del "buen gusto", así para Arendt el gusto sería la cultura animi que posibilita que las personas sean confiables para cuidar de un mundo de apariencias. Lessing se refería al genio como un hombre de gusto afortunado: "aquello que lo conmueve, conmueve. Lo que le agrada, agrada. Su gusto afortunado es el gusto del mundo" "21. Más allá del pedante que entiende sin sentir y del mundano que disfruta sin entender; el hombre con gusto afortunado, sabe reconciliar el entendimiento con la sensibilidad y puede proyectar el sentir de los demás en su propio sentir, lo que hace posible el sentimiento comunitario, abriendo paso al sentido del gusto en la política.

\section{Elementos de aplicabilidad del juicio del gusto de Kant al ámbito político}

Después de plantear la importancia política de juzgar y del sentido del gusto, procedo a analizar ciertas características del juicio del gusto de Kant para efectos políticos, tal y como lo interpretara Arendt. Y dichos criterios serían los siguientes: amplían los márgenes de comprensión, se construyen en el ámbito público, develan la comunicabilidad universal de los sentimientos, no buscan la "verdad" y dejan ver que no todo es estratégico, que el goce desinteresado de la experiencia estética es posible no sólo respecto al arte sino también hacia los seres humanos. Voy a los argumentos.

\subsection{Los juicios del gusto amplían los márgenes de comprensión}

Según Arendt, uno de los aspectos del juicio del gusto que permite aplicársele a la política es su "modo de pensar extensivo" pues nos permite aproximarnos a la comprensión del "otro". No es poca cosa. Si uno de los principales retos ético-políticos es justamente aprender a salir de ensimismamiento y/o egoísmo para querer y/o poder interesarse en los demás. El juicio estético viene muy ad hoc porque coadyuva a la amplitud espiritual del Sujeto.

El punto aquí no es que el juicio estético demuestre que los seres humanos somos sensibles y vulnerables en el ámbito privado porque en general así es, para bien o para mal... sino que podemos tener la capacidad de sensibilizarnos por los "otros", distantes, extraños y hasta distintos...

El juicio del gusto deja ver que podemos imaginar y sentir experiencias ajenas a uno mismo y por esta condición es que puede enfocarse al ámbito político. Una obra de arte puede ayudarnos a comprender muchas ideas, experiencias, situaciones, tanto o más que un discurso racional; y siguiendo esta línea, si podemos admirar el arte

H. Arendt y M. McCarthy, Correspondencia entre Hannah Arendt y Mary McCarthy, trad. A. María Becciu, $2^{\mathrm{a}}$ edic., Barcelona, Lumen, 1999, p. 123.

21 H. Arendt, Hombres en tiempos de oscuridad, trad. C. Ferrari y A. Serrano de Haro, Barcelona, Gedisa, 2001, p. 14. 
de cualquier otra cultura, ¿por qué no a otro ser humano, por distinto y distante que parezca? Una de las cualidades humanas que nos permite actuar como seres políticos es que podemos situarnos en los potenciales puntos de vista de los otros para juzgar imparcialmente aquello que tenemos en común. En este aspecto, la capacidad de juicio en su sentido kantiano puede ser fundamental para el hombre como ser político pues supone la capacidad de ver cosas no sólo desde el punto de mira personal sino también según la perspectiva de los "otros". Y lo asombroso fue que Kant descubriera este fenómeno en toda su grandeza en el fenómeno del gusto, ajeno al campo político y también al uso de la razón.

En la Crítica del Juicio Kant considera que no es suficiente estar de acuerdo con el propio yo, sino que faltaría ser capaz de "pensar poniéndose en el lugar de los demás", lo que llamó "modo de pensar extensivo". Cito de Kant:

un hombre amplio en el modo de pensar puede apartarse de las condiciones privadas subjetivas del juicio, dentro de las cuales tantos otros están como encerrados, y reflexiona sobre su propio juicio desde un punto de vista universal (que no puede determinar mas que poniéndose en el punto de vista de los demás) ${ }^{22}$.

Recordemos la antigua plegaria a Dios del rey Salomón para que le fuera concedido un corazón comprensivo como el mejor de los dones que el hombre puede recibir y desear porque sabía que ni la pura reflexión, ni el simple sentimiento, sino sólo un corazón comprensivo nos hace soportable el vivir en un mundo común con otros que siempre son extraños y nos hace así mismo, soportables para ellos. Así por ejemplo, cuando se abordan temas de orden sexual o religioso, que fácilmente pueden herir susceptibilidades, nos damos cuenta de lo fácil que es cerrarnos en visiones etnocéntricas y rechazar o burlarse de los que ven las cosas de otra forma.

Para Arendt el don de un corazón comprensivo es la imaginación: "sin este tipo de imaginación, que en realidad es la comprensión, no seríamos capaces de orientarnos en el mundo. Somos contemporáneos sólo hasta donde llega nuestra comprensión"23. Sólo mediante la imaginación podemos acercarnos al "otro" (siempre único y distinto) emocional y epistémicamente, comunicarnos, verlo y comprenderlo. La imaginación como dijo Wordsworth no es sino otro nombre para la amplitud del espíritu.

La imaginación es una facultad que permite comparar nuestros juicios con otros juicios posibles y ponerlos en el lugar de cualquier otro. "La imaginación, a saber, la facultad de hacer presente aquello que está ausente" ${ }^{24}$. Mediante la imaginación podemos hacer presentes a los otros y así es que se mueve en un espacio potencialmente público, adoptando la postura del ciudadano cosmopolita kantiano.

La imaginación es la que permite esa proximidad de la comprensión pero también establece la distancia necesaria para el juicio. El pensar poniéndose en el lugar de los demás posibilita "un acuerdo potencial con los demás" para lograr finalmente algún consenso; sin embargo, según Arendt: "el ardid del pensamiento crítico no es una empatía desmesuradamente amplia gracias a la cual se puede saber qué aconte-

I. Kant, Crítica del juicio, op. cit., p. 247.

23 H. Arendt, "Comprensión y política" en De la historia a la acción, trad. F. Birulés, Barcelona, Paidós, 1995, p. 46.

24 H. Arendt, Conferencias sobre la filosofia política de Kant, op. cit., p. 124. 
ce realmente en la mente de los otros" 25 . Esto es, que Arendt claro que confía en la comprensión pero en forma alguna aspira a la empatía radical en la que nadie cree.

\subsection{Los juicios del gusto se construyen en el ámbito público}

El juicio estético y el juicio político comparten el requisito fundamental de la apariencia pública, presuponen un mundo en común. Uno de los datos que conecta al arte y a la política es que ambas son fenómenos del mundo público, ni el arte ni la política son realidades solipsistas. A diferencia de la lógica que sólo depende de la presencia del yo, el juicio depende de la presencia de otros. El juicio del gusto se ejerce en la sociabilidad, es intersubjetivo en cuanto que nace de los sentimientos que los sujetos tienen en común, de lo que pueden comunicarse entre ellos, y así es que nace en el "mundo". Mediante la actividad del juicio se produce ese compartirel-mundo-con-los-demás. En este sentido, Ronald Beiner sostiene que:

el análisis kantiano del gusto se basa en un concepto de "intersubjetividad" (...). Está de más decir que Kant no utilizó el término "intersubjetividad"; habla de "pluralismo" que definió en su Antropología como aquel modo de pensar que consiste en no considerarse ni conducirse como encerrando en el propio yo el mundo entero, sino como un simple ciudadano del mundo ${ }^{26}$.

Y uno es un ciudadano del mundo por el simple hecho de ser hombre, tal es la "existencia cosmopolita"27. El espíritu cosmopolita que le hace decir a Dante: "mi patria es todo el mundo". Según Arendt, cuando se juzga el ámbito público uno debe orientarse como espectador del mundo (Weltbetrachter) y la validez de los criterios de los espectadores de alguna obra artística o de la política dependen de la aceptación pública. Así como la aprobación o desaprobación de alguna obra estética finalmente depende de lo que pueda hacer sentir a los espectadores, de lo que pueda comunicar públicamente, así también "las acciones referentes al derecho de otros hombres son injustas, si su máxima no admite publicidad"28. De ahí que en la filosofía moral de Kant el examen público de las ideas sea un criterio moral de rectitud, lo moralmente correcto hace coincidir lo privado con lo público. Para el filósofo de Königsberg, las máximas privadas deben someterse a un examen gracias al cual descubro si puedo hacerlas públicas; de lo contrario, la insistencia en el carácter privado de la máxima y por consiguiente, la retirada del ámbito público sería una característica del mal: no se siente demasiada ansia por expresar alegría ante la muerte del padre, en cambio, no se tendrá escrúpulo alguno al expresar públicamente que se ama el trabajo filosófico. El criterio es la comunicabilidad y la pauta para decidir sobre ello es el sentido común, donde juzgar por sí mismo pareciera coincidir con el juzgar en voz alta.

\footnotetext{
Ibidem, pp. 84-85.

Ibidem, p. 209.

27 Un cosmopolita, según el uso francés registrado en el año 1738, es un hombre que se mueve cómodamente en la diversidad, se encuentra cómodo en situaciones que no tienen ningún vínculo o paralelo con aquello que le es familiar. El mismo sentido de la palabra apareció en el idioma inglés antes que en el francés, pero no fue muy empleado hasta el siglo XVIII. En vista de los nuevos términos empleados para referirse al hecho de estar en público, el cosmopolita se constituyó en el hombre político perfecto. Cf. R. Sennet, El declive del hombre público, trad. G. di Masso, Barcelona, Península, 2002 p. 49.

28 I. Kant, La paz perpetua, trad. A. Sánchez Rivero y F. Rivera Pastor, Madrid, Espasa Calpe, 8ª ed., 1984, p. 151.
} 
La validez pública del juicio del gusto deja ver que los seres humanos tenemos "algo en común" por lo que podemos comunicarnos y por lo que podemos aproximarnos espiritualmente al "otro" y que se deja ver en la coincidencia de la inteligible unidad de la conciencia trascendental con la unificación de todas las conciencias empíricas producida en la publicidad.

Aunque en este aspecto, habría que puntualizar que cuando Kant piensa en lo "público" se refiere a un público cultivado, mientras que el sentido arendtiano de lo público pretende un espectro de intersubjetividad donde nadie quede excluido. No obstante, nuestra filósofa también desconfiaba de las mayorías porque a veces pueden participar desde negociaciones previas o por alguna suerte de manipulación ideológica; de ahí que planteara ejercer el pensamiento y juicio para la participación política.

\subsection{Los juicios del gusto no buscan la "verdad"}

Los juicios del gusto en Kant no buscan la verdad, ni informar o explicar como los juicios sintéticos a priori. El juicio estético surge del placer meramente contemplativo, no expresa un modo de ser de las cosas sino un modo de sentir las cosas, al sentimiento de este último tipo de placer Kant lo llama "gusto", así se entiende que todavía en 1787 se refiera a la Crítica del Juicio como "Crítica del gusto". Kant consideraba que los juicios estéticos no se refieren al objeto, sino al sujeto totalmente y al sentimiento que esa representación provoca en el sujeto, sin relacionarse con concepto o con conocimiento alguno. Cito de la Crítica del Juicio: "el juicio del gusto no es, pues, un juicio de conocimiento; por lo tanto, no es lógico, sino estético, entendiendo por esto aquel cuya base determinante no puede ser mas que subjetiva" 29 .

El juicio del gusto toma su objeto simplemente como motivo de un libre movimiento de complacencia. El predicado del juicio del gusto no es un concepto sino el sentimiento de placer y desplacer, no cabe fundarlo en algo, hay que ensayarlo como cosa propia. Decía Arendt que cuando pretendían demostrarle por qué le gustaba tal poesía o escultura, "se tapaba los oídos".

Ahora bien, el gusto es discriminante porque al decir si algo agrada o desagrada está escogiendo, pero esta elección depende de otra: se puede aprobar o desaprobar el hecho mismo del goce y todas estas aprobaciones o desaprobaciones son pensamientos a posteriori, de donde resulta propiamente el juicio estético ${ }^{30}$. Para Kant, lo que simplemente place en la percepción es agradable pero no bello. Lo bello place pero ya en la representación; sólo cuando no se puede seguir estando afectado por la presencia inmediata puede ser juzgado como bello. Es en la operación de la reflexión cuando se habla de juicio y ya no sólo de gusto, porque, aunque todavía "gusta", se ha establecido cierta distancia para asumir el desinterés requerido para aprobar o desaprobar, para evaluar algo en su justo valor. Kant denominó "operación de la reflexión" no a la percepción directa del objeto sino a la reflexión de la representación. Y esta representación es la que juzgamos bella o no. Así el juicio del gusto es reflexionante. El placer en el que se basa el juicio estético es un placer mediado, no es una gratificación inmediata. Y esta reflexión que mediatiza al juicio del gusto siempre se verá enriquecida por el debate público; de manera que si bien el gusto es personal, esto no quita que podamos exponerlo y compartirlo con los demás.

I. Kant, Crítica del juicio, op. cit., pp. 131-132.

30 Cf. H. Arendt, Conferencias sobre la filosofia politica de Kant, op. cit., pp. 127-128. 
Y en este sentido, para Arendt al juzgar el ámbito político no pretendemos alcanzar "verdades científicas" sino "ideales políticos" y los objetivos políticos muy probablemente no tengan fundamentación racional... La política ha de ser resultado de la deliberación pública y del consenso, así se entiende que una de las frases más repetidas de su obra sea que el "sentido de la política es la libertad"31. Arendt consideraba pedantes y peligrosas a los pilares de la verdad (bien, civilización, progreso, honor, etc.) si muchos de ellos han legitimado injusticias, muertes y guerras... "Los errores más terribles han sustituido a las verdades más conocidas"32. De ahí que se decante más por la sensibilidad y la imaginación que por la propia razón o la "verdad" en asuntos humanos, resultando una suerte de intersección hermenéutica del juicio del gusto con el juicio político.

Las opiniones políticas son como los juicios del gusto, persuasivos, se caracterizan por la esperanza de llegar a algún acuerdo con el otro, a diferencia del argumento científico que mediante la comprobación obliga de una u otra forma al acuerdo mediante un proceso de pruebas irrefutables. La verdad es un valor de coacción. Pero en el arte y en la política no hay verdades, a lo que podemos aspirar es a la creación de espacios públicos de participación donde la palabra de todos sea escuchada. Los juicios nunca tienen un carácter concluyente, jamás obligan al asentimiento por medio de una conclusión lógicamente irrefutable, no imponen validez universal, más bien juzgan de manera personal y contingente, de donde surgen consensos pero no verdades últimas.

Así la estética kantiana consentirá a Arendt formular una teoría del juicio político sobre la base de la deliberación pública y el gusto, que el teleologismo racional de Aristóteles no le había podido suministrar.

\subsection{Comunicabilidad universal de los sentimientos en los juicios del gusto}

En este apartado dejaré ver un dato que a Arendt le interesa subrayar: el gusto comunica "algo" de forma universal y sin concepto, como si todos los seres humanos tuviéramos el mismo programa para procesar la información proveniente de las sensaciones, Kant le llama a ese algo “sentido común”. Ahora bien, según Rivera de Rosales Arendt confunde los dos significados kantianos del "sentido común": el sentido común lógico o sano juicio (sano entendimiento) y el sentido común estético o gusto, el primero juzga mediante conceptos y el segundo mediante el sentimiento ${ }^{33}$. Para efectos de este trabajo, no me detendré en dicha crítica porque entiendo que a Arendt lo que le interesaba era dejar ver que subsiste lo común ante la pluralidad humana, lo que nos capacita para integrarnos en una comunidad política, libremente, sin coerción.

Si el juicio del gusto ha de ser válido para todos es porque ha de haber algo común en todos los hombres que posibilita la coincidencia de criterios en torno a lo bello. De ahí que para Kant los juicios del gusto sean a priori por la universalidad subjetiva que se cumple en el sentir de los sujetos. Cito de la Crítica del Juicio: "el gusto, pues, es la facultad de juzgar a priori la comunicabilidad de los sentimientos que están unidos con una representación dada (sin intervención de un concepto)"34.

\footnotetext{
H. Arendt, ¿Qué es la política?, trad. R. Sala Carbó, Barcelona, Paidós, I.C.E./U.A.B., 1997, p. 61.

H. Arendt, Hombres en tiempos de oscuridad, op. cit., p. 21.

33 Cf. J. Rivera de Rosales, "Kant y Hannah Arendt. La comunidad del juicio reflexionante", Ideas y valores 128, 2005, pp.1-29, aquí p. 22.

34 I. Kant, Crítica del juicio, op. cit., p. 248.
} 
La belleza es representada como objeto de complacencia general y es experimentada como válida para todo el mundo, sin que pueda empero, indicarse la regla general de la que él sería un ejemplo. La subjetividad del juicio estético se remedia por el hecho de que el mismo objeto también aparece ante otros, aunque los otros sean distintos física y culturalmente, lo que convence a los hombres de que pertenecemos a la misma especie y que es posible la intersubjetividad del mundo. Y con esto he llegado a uno de los aspectos que vincula al juicio estético con el juicio político: la comunicabilidad de los sentimientos. El gusto es la percepción más íntima de todas y es sin embargo, compartible. Kant decía que:

La cultura de las facultades del espíritu, por medio de aquellos conocimientos previos que se llaman humaniora, probablemente porque humanidad significa, por una parte, el sentimiento universal de simpatía, por otra parte, la facultad de poderse comunicar universal e interiormente, propiedades ambas que, unidas, constituyen la sociabilidad propia de la humanidad, por medio de la cual se distingue del aislamiento de los animales ${ }^{35}$.

Aunque en una primera instancia, pareciera que el gusto es estrictamente personal, Arendt decía que: "en cuestiones de gusto no hay disputa. Ningún argumento podrá persuadirme para que me gusten las ostras si resulta que no me gustan" ${ }^{36}$. Podríamos suponer por ejemplo, que a alguien no le guste Picasso y que sea respetable el que no le guste pero si se atreviera a afirmar que Picasso no es un buen pintor entonces tendría la exigencia de argumentarlo y con ello de exponer sus ideas al debate público. Así, más adelante sostiene siguiendo a Kant, "en el gusto se supera el egoísmo"37 porque en los juicios del gusto se toma en cuenta los posibles juicios de los demás, aunque los juicios del gusto sean personales, no permanecen encapsulados, muy por el contrario se construyen desde la persuasión y el debate. El "buen gusto" puede oponerse a las inclinaciones del individuo y aunque no se pueda imponer, está claro que se construye con los demás si aspira a ser "buen gusto".

El gusto se comparte, no es una imposición. ¿Hasta qué punto se debe obligar al otro a estar de acuerdo con los propios juicios acerca de lo bello? Sólo se puede cortejar o solicitar el acuerdo de los otros, lo que los griegos llamaban persuasión (peithein) y en esta actividad persuasiva se está recurriendo realmente al sentido comunitario. Cito de Kant: "el juicio del gusto exige la aprobación de cada cual (...). Se solicita la aprobación de todos los demás, porque se tiene para ello un fundamento que es común a todos" ${ }^{38}$.

La persona que juzga sólo puede "galantear en busca del consentimiento del otro" con la esperanza de llegar por último, a un acuerdo con él. Kant era consciente de la cualidad pública de la belleza y por esa importancia pública insistió en que los juicios del gusto están abiertos a discusión. El gusto es el resultado de un continuo proceso de formación de fuentes plurales.

El me agrada o me desagrada pareciera ser un sentimiento tan privado e incomunicable y sin embargo está enraizado en el sentido comunitario y por tanto abierto

\footnotetext{
Ibidem, p. 322.

Hannah Arendt, Conferencias sobre la filosofia política de Kant, op. cit., p. 124.

Ibidem, p. 125 y cf. I. Kant, Crítica del juicio, op. cit., p. 226.

I. Kant, Crítica del juicio, op. cit., pp. 174-175.
} 
a la comunicación, una vez transformado por la reflexión que toma en cuenta a los demás y sus sentimientos. Así Arendt consideraba que: "el gusto recurre al sentido común, es la antítesis misma de los «sentimientos privados» (...), no hay en él una implicación de los intereses vitales del individuo ni de los intereses morales del yo"39. El sentido común dice que cada cual estará conforme con nuestro juicio sin recurrir a la imposición y sin perder imparcialidad. Esto no presupone algún tipo de extensa empatía ni un dejarse hechizar por la mente de los otros, sino el compromiso de pensar por sí mismo. "Sentir en común y juzgar por sí mismo".

Según Arendt, si los hombres pueden llegar a algún acuerdo respecto al arte mediante la persuasión, pese a las diferencias culturales de los sujetos que juzgan, entonces podría suponerse que subsisten condiciones hermenéuticas comunes en todos los seres humanos; por lo que podríamos hablar de "sentido común". Y dichas condiciones que posibilitan el "sentido común" tal vez también podrían valer para el espacio político. Por el contrario, de suponer la imposibilidad de lo común, de la comunicación o alguna suerte de relativismo radical, tendríamos que aceptar cualquier arbitrariedad como "obra de arte", "objetivo político" o "bien público".

Además, mediante el sentido común se revela la compatibilidad de la libertad individual con la libertad de los demás porque sin ceder en los gustos se puede coincidir voluntariamente con el gusto de los demás, lo que finalmente permite la comunicación en el arte y en la política. El sentido común no aparece como un dato psicológico sino como la condición subjetiva de toda comunicabilidad. El enfoque arendtiano del sentido común no se refiere a algún consenso empírico, ni a alguna dimensión sociológica; más bien se refiere a nuestro sentido del mundo y de la intersubjetividad, una cualidad producida en común. Los franceses tienen la muy sugestiva denominación de le bon sens para desvelar la naturaleza de un mundo en común.

\subsection{Goce desinteresado en los juicios del gusto}

Por último, Arendt rescata la actitud "desinteresada" que tiene el hombre respecto al arte (según Kant) para aplicarla a lo humano. Kant sostenía que lo bello nos enseña a amar sin interés propio y que en general, las obras de arte no son para "usarlas", cito: "el juicio del gusto, mediante el cual algo se declara bello, no debe tener interés alguno como fundamento de determinación" ${ }^{40}$. El placer puro es desinteresado, place sin concepto, sin intención objetiva y sin pretensión de verdad. De ahí que para Kant, el placer estético sea superior.

Pero ¿en qué sentido la facultad de sentir ha de ser superior? Desde la interpretación de Deleuze, el sentido kantiano del placer superior no debería estar ligado a ninguna atracción sensible, ni a ninguna inclinación intelectual. La facultad de sentir sólo puede ser superior si es desinteresada en su principio. El desinterés del juicio estético corresponde al hecho de estar libre de los propios intereses privados y me parece que ésto debería tener analogía con el trato humano, que no debe ser mediatizado por el "uso" o por algún interés.

La posibilidad que tenemos de sensibilizarnos desinteresadamente por el arte deja ver que las operaciones psicoafectivas no son sólo estratégicas. Y si podemos contemplar el arte de forma gratuita pues cuanto más podríamos admirar y respetar la

H. Arendt, Entre el pasado y el futuro, op. cit., p. 234.

40 I. Kant, Crítica del juicio, op. cit., p. 248. 
vida humana, supongo. Según Haidt, las personas pueden verse muy afectadas por la visión de un extraño ayudando a otro, evidenciando que podemos tener un sentimiento estético ante los actos virtuosos y estar atraídos por su belleza, lo que correspondería a la conexión entre el juicio estético y el sentimiento moral.

Esta analogía entre la experiencia estética y el interés categórico por lo humano ya ha sido enfocada por otras vertientes. En una Conferencia sobre políticas culturales por ejemplo, se refirió un texto de la UNESCO que afirmaba que la calidad de vida dependerá en gran medida del modo en que se inculque a los jóvenes la creatividad y la capacidad de disfrute estético. Alfonso López Quintás decía al respecto: "la práctica del desinterés estético promociona en el espíritu humano el respeto a las realidades de su entorno. Respetar significa conceder libertad a cada realidad para ser lo que es y lo que está llamada a dar de sí" ${ }^{\prime 1}$.

No obstante, pudiera ocurrir que se respete más a las obras de arte que a la vida humana como tal. Tomás Abraham cuenta que en Italia cuando las Brigadas Rojas realizaban actos de terrorismo, la amenaza de destruir el patrimonio cultural en el suelo italiano decidió a las autoridades a tomar definitivamente en serio las exigencias de los terroristas ${ }^{42}$. Aunque en este aspecto quizá habría que preguntarnos si quienes protegen algún patrimonio cultural realmente tienen interés estético por la belleza o sólo por el valor económico que representan... pero independientemente de estas suspicacias, a lo que quiero llegar es a rescatar la disposición desinteresada que se puede tener respecto a la belleza pero aplicada también a cualquier ser humano. Después de todo, la admiración y el respeto a la vida no creo que deba exigir silogismos sofisticados para su aceptación, supongo que debería ser un principio casi axiomático.

Arendt no aborda las estrategias didácticas para aprender a ser "desinteresado", comprensivo e imparcial en nuestros juicios; en parte porque su enfoque no es pedagógico sino filosófico y en parte también porque Arendt misma reafirma la idea kantiana de que el talento peculiar del juicio no se puede enseñar, sólo ejercitar ${ }^{43}$. Ojalá existiera alguna forma de enseñar y/o aprender a superar el autismo espiritual... aún sigue siendo un reto ético y pedagógico saber cómo educar los sentimientos para ampliar el margen de comprensión entre los hombres...

\section{Conclusión}

Desde el enfoque político de Arendt, uno de los aspectos centrales de la ciudadanía es el derecho y la obligación de juzgar el ámbito público pero este sentido del juicio político no ha de partir propiamente de la razón, del pensamiento, de alguna verdad o de "buenas intenciones" sino de las condiciones de posibilidad del juicio del gusto de Kant. Dicha lectura se construye a partir de las siguientes características del juicio del gusto de Kant que Arendt reinterpreta con miras políticas:

a) Amplían los márgenes de comprensión. Al juzgar una obra de arte, de alguna forma nos aproximamos emocionalmente y mentalmente a lo que la obra nos quiere o puede decir, y esta posibilidad deberíamos hacerla extensiva en política para ampliar los márgenes de comprensión a la otredad

\footnotetext{
A. López Quintás, La experiencia estética y su poder formativo, Navarra, editorial Verbo Divino, 1991, p. 18.

Cf. Th. Abraham, Situaciones postales, Barcelona, Anagrama, 2002, p. 158.

43 Cf. H. Arendt, Conferencias Sobre la filosofia política de Kant, op. cit., p. 17.
} 
b) Se construyen en el ámbito público, donde dejamos ver que es posible superar el egoísmo natural y mostrar apertura a la intersubjetividad y a la razonabilidad

c) Develan la comunicabilidad universal de los sentimientos porque mediante el arte podemos comunicarnos pese a la pluralidad cultural, dejando ver que subsiste "algo" en común que nos permite comunicarnos como humanidad y alcanzar el "sentido común", que muy probablemente debería guiar los objetivos políticos, superando con ello los peligros del relativismo axiológico o cultural

d) No buscan la "verdad". Los juicios del gusto y los juicios políticos alcanzan validez desde la deliberación pública, no desde la exigencia rigurosa de algún método científico, ni desde la imposición de alguna "verdad", ni por objetivos preestablecidos.

e) Juzgar el arte o la política nos debería mostrar que no todo es estratégico, que el goce desinteresado de la experiencia estética es humanamente posible no sólo respecto al arte, sino también respecto a los más altos valores ético políticos, respecto a la vida misma y por supuesto, respecto a cualquier ser humano. 